\title{
A Tale of Failure: Indigenous Language Radio Broadcasting in Zimbabwe
}

\author{
Memory Mabika \\ Department of Communication and Applied Language Studies, \\ University of Venda, Thohoyandou, South Africa \\ Email: memory.mabika@univen.ac.za
}

\section{Professor Abiodun Salawu}

Department of Communication, North-West University, Mafikeng Campus, Mmabatho, South Africa

\section{Doi:10.5901/mjss.2014.v5n20p2391}

\begin{abstract}
Using the electronic colonialism theory and globalisation approach, the study reflects on the distinctive features of indigenous language radio broadcasting stations in Zimbabwe. This is done in an effort to establish how the prevailing radio broadcasting landscape is limiting the use of minority languages in this multilingual nation. Studies reveal the importance of indigenous languages and expound on how radio broadcasting can effectively enhance indigenous languages revitalisation processes. However, due to the previous and current political contexts in Zimbabwe, indigenous language radio broadcasting has continued to create an atmosphere where minority languages are not given necessary recognition, leading to their exclusion from most of the existing radio stations. Qualitative data were collected using three instruments, namely interviews, focus groups discussions and document analysis. Findings reveal that most indigenous languages in Zimbabwe have never been developed beyond their oral use by speakers in their confined locations. This makes any effort to use these languages for broadcasting a serious challenge since speakers and non-speakers do not value these languages. The government's stringent Broadcasting Services Act of 2001 (BSA) has also made the usage of radio broadcasting in preserving minority languages an almost impossible task. It is the contention of this paper that no positive change is possible to radio broadcasting if the existing BSA is not revisited, in order to broaden the broadcasting landscape so as to introduce community stations which can broadcast to specific communities in indigenous languages spoken in those areas.
\end{abstract}

Keywords: Broadcasting, Indigenous languages, Language revitalisation, Minority languages, Zimbabwe

\section{Introduction}

Since their inception, the media as disseminators of news are considered principal institutions that have the mandate to facilitate dialogue and provide relevant information to the citizenry, from which members of the public get a better understanding of their society (McCombs \& Shaw, 1993; Browne, 2008). Humans, mainly, interact by exchanging information in a language understood by the people involved in the communication process. Therefore, effective communication can only take place if a common language is used. Communicating in indigenous languages, it has been noted, enhances social cohesion, which facilitates the preservation of African cultures (Salawu, 2006).According to Sonderling (2009: 85) "Language is important and central in all aspects of our lives, from face-to-face situations to communication through the mass media". For that reason, using indigenous languages to interact with the masses through the media, particularly radio, enhances the effectiveness of mass communication. Studies have shown that indigenous language radio broadcasting is the most effective channel of mass communication since it reaches more peripheral areas than other media, and is easily understood by the audiences (Mufwene, 2002; Manyozo, 2009).

Many scholars argue that the global spread and acceptance of English as a world lingua franca poses serious threats to the existence of most indigenous languages in Africa and the world over (Ndhlovu, 2004; Salawu, 2006; Magwa, 2008; Rao, 2009). However, Maseko and Moyo, (2013:252) argue that stronger indigenous languages such as Shona and Ndebele also contribute to the killing of other smaller indigenous languages. They claim that, because Shona and Ndebele are recognised as national languages, other languages considered minor, hence have remained on the fringes of the sociolinguistic milieu and have not received any recognition nationally (Ibid). When some languages are used to exclude other languages, then it becomes evident that there is something amiss with the country's language policy (Magwa, 2008). 
Zimbabwe is a country that endured colonialism and a protracted war of liberation from colonial rule. Therefore, one would expect the government to use its political power to safeguard the sovereignty of the people. This can be done by ensuring the vibrancy of its indigenous languages and prevent their dominance by foreign ones such as English or a few indigenous languages such as Shona and Ndebele. It is also imperative that most, if not all, indigenous languages spoken in the country by indigenous people are equitably recognised and used in education, government documentation and the media, particularly the ubiquitous radio broadcasting. Thus, different communities will access government documents in their languages, schools teach will the dominant languages spoken in those communities, and indigenous language radio stations in these areas will also utilise the local languages understood by the majority for broadcasting.

Using the electronic colonialism theory and globalisation approach, this study examines the distinctive features of indigenous language radio broadcasting stations in Zimbabwe, in an effort to understand how indigenous languages are being side-lined and the implications of such an action. The following sub-questions were utilised in this study:

- What are the features of indigenous language radio broadcasting stations in Zimbabwe?

- How is the prevailing radio broadcasting landscape limiting the use of minority languages in this multilingual nation?

- What is the impact of the existing indigenous language radio broadcasting trends on indigenous language revitalisation in this multilingual and multicultural nation?

\section{Radio Broadcasting from Rhodesia to Zimbabwe}

From 1933 when radio broadcasting was first introduced in the country to the early sixties, the then Southern Rhodesia broadcasting relied on broadcasting from outside the country. This all ended when Southern Rhodesia became a separate country, and the Rhodesia Broadcasting Corporation was set up. The RBC, in its early days in the early sixties, launched a local broadcasting service on short-wave and broadcast from a site geographically in the centre of Zimbabwe at Guinea Fowl near Gweru (Miller, 2007). Though at the time broadcasting served an area within a 200-mile radius of Gweru by 1968, the RBC had expanded its services to Salisbury where Radio Jacaranda was launched, followed by Radio Matopos in Bulawayo and Radio Manica, in Umtali (Deacon, 2009). At independence, in 1980, the RBC had opened various FM stations in the Salisbury and Bulawayo areas, and the network had gradually expanded to 22 community stations covering the whole country (Miller, 2007). However, when Mugabe's ZANU PF government gained political power, after the first democratic election in 1980, they just adopted RBC which they renamed ZBC, but reorganized radio broadcasting into only four radio stations country wide, namely SFM (English), Power FM (English), Radio Zimbabwe (Shona and Ndebele) and National FM which broadcasts in Shona and Ndebele, and in 13 other minority indigenous languages (Chari et al, 2003). The community radio stations were shut down.

The Zimbabwe broadcasting system is complex and has been controlled by the state from the pre-independence era. However, history was made when two free-to-air broadcasting national radio licenses were granted to Star FM and ZiFm, which began broadcasting in June and September 2012, respectively. They both broadcast in English, Shona and Ndebele although English seems to be their dominant language of broadcast.

There are also more than six Zimbabwean radio stations operating in the Diaspora, but broadcasting into the country. All these foreign-based radios, with the exception of SW Radio Africa, broadcast over the Internet (Pasura. 2006). Internet radios, are operating without much operation costs and legislative hurdles, and are a fast growing business among the Zimbabweans in and outside the country. These radios include SW Radio Africa, Afrosounds, Zonet, Zimnet, and Shayafm.

\section{Usage of Indigenous Languages in the Media (with a Special Focus of Radio Broadcasting)}

Zimbabwe, a former colony of Britain, is a multilingual and multicultural nation which has more than 15 indigenous languages and English as its official language and a population of approximately 13 million people. At independence, the Zimbabwe government decided to ignore most indigenous languages and to concentrate only on a few already advanced indigenous languages, such as Shona and Ndebele (Magwa, 2008). Written Shona and Ndebele had already developed at the time since they were subjects taught at secondary level in local schools. Naturally, these two indigenous languages received the first preference countrywide over other underdeveloped minority languages. Giving the platform to a few local languages, which had readily available educational material made sense at the time. However, this has proved difficult to reverse many years after independence (Magwa, 2010).

Indigenous languages are vital in all sectors of business, government, education and the media. Fourie (2001:448) claims that "the particular role of news in our lives is therefore inextricably linked to the general role that language plays in 
society." Sonderling (2009:84) delineates the relationship between language and society when he says that: "language is created by society, but it also creates or re-creates society." There is no doubt that the ubiquitous radio broadcasting play an important role of disseminating information and in shaping all aspects of the receiver's way of thinking, and way of life.

Zimbabweans, like most other people in the world, have access to a range of media such as television, newspapers, mobile phone technologies and a number of Internet-based media. However, most of these media technologies are accessed in English, the principal official language of the country and are not accessed by many, particularly those in rural areas. Newspapers are still popular and accessible by many in urban areas. However, most publish in English, with the exception of Kwayedza (Shona) and Umthunywa (Ndebele).

There are two national television channels ZTV 1 and ZTV 2, all under the state-run Zimbabwe Broadcasting Corporation (ZBC). Both stations use English as the principal language of broadcast, although there are a few Shona and Ndebele broadcasts, which consist of news bulletins, local drama and current affairs. The situation is almost similar in radio broadcasting.

In Zimbabwe, out of the four ZBC radio stations (SFM, Power FM, Radio Zimbabwe, National FM) and the two privately owned (StarFM and ZiFM), there are only two indigenous language radio stations, namely Radio Zimbabwe and National FM. Radio Zimbabwe is limited to only Shona and Ndebele, the only two local languages officially recognised as national Languages. Only one national radio station, 'National FM,' broadcast in most of the local minority languages. It broadcasts in Shona and Ndebele, as well as in 13 other minority indigenous languages.

Minority language listeners have become very active participants in programmes which are broadcast in their own languages (Mumpande, 2006). However, Mano (2006) points out that the capability of one station to sufficiently broadcast in all indigenous languages in a multilingual and multicultural nation such as Zimbabwe is a fallacy. Similarly, Ndhlovu (2004) bemoans the way minority languages are treated in the Zimbabwe broadcasting media. He argues:

While NFM is meant to cater for minority languages that include Doma, Chikunda, Chewa, Yao, Hwesa, Barwe, Venda, Sotho, Kalanga, Shangani, Tonga, Xhosa and Tshwawo, Shona and Ndebele programmes take up most of the airtime. - - - Minority groups are always unfairly left out of the national agenda (Ndhlovu (2004: 139-140).

\section{Theoretical Framework}

The study adopted the Electronic Colonialism Theory (ECT) and the globalisation theory. The ECT was expounded by Thomas McPhail, who began his career in the early 1980s while working with Marshall McLuhan who propounded the global village concept. ECT is a brainchild or another label of cultural imperialism, which has received numerous labels over the years (Rauschenberger, 2003:6). ECT is premised within the realm of postcolonial discourse which is defined as a period coming after the end of colonialism (Childs and Williams, 1997:1).

Thomas McPhail, using the ECT, describes culture as basically reflecting attitude and that it is learned. McPhail further laments that repeated exposure through various media, collectively, have the real potential to displace or alter previous cultural values, language, lifestyles or habits, activities, or family rituals (McPhail, 2010).

Globalisation is a slippery process. It is a widely used and misused concept that cannot be pinned down to one universally accepted definition and/or description since it means and/or implies different things to different people (Kamwendo, 2008: 84). It can be defined as the intensification of worldwide social relations which link distant localities in such a way that local happenings are shaped by events occurring many miles away and vice versa, making many of the currently existing borders and boundaries irrelevant (Giddens, 1990:64). The process of globalisation, which is not valuefree, innocent and/or self-determining, is associated with the technological advancement, spread of democracy and increased human movement, which results in the contamination of indigenous cultures and the death of some indigenous languages (Nsibambi, 2001:1).

Due to globalisation, the interconnectedness of communities, both locally and globally, has turned the whole world into McLuhan's presumed global village where some dominating languages have been given impetus to thrive, while weaker ones become more vulnerable and dissolve over time. The global usage of English, for instance, has increased the demand for proficiency of this language to enhance global communication. In Zimbabwe, Shona and Ndebele have remained dominant languages socially and in indigenous language radio broadcasting stations, casting a dark shadow over other minority indigenous languages. However, the English language has continued to dominate indigenous languages in all government systems and the media, particularly radio broadcasting despite being alien to the local inhabitants.

In conceptualising the cultural globalisation strand, many particularly from developing nations, hold negative views. They view cultural globalisation as a process of neo-colonialism where specific cultural traits from a few developed societies are universalised at the expense of other cultures and languages (Nsibambi, 2001; Salawu, 2006). 
The ECT and cultural globalisation are useful to this study since they can help to explain some of the roots of language problems being encountered by Zimbabweans and which have left most minority languages vulnerable to threats from within and without. Globally, when languages die rapidly as feared by some scholars (Salawu, 2006; Manyozo, 2009), it signifies the death of culture that is everything that is shared by a people in their specific different communities in their own indigenous languages. Both the cultural globalisation strands, and ECT concur that there is power inequalities between different social groups. This has dire consequences on the future of most indigenous languages globally. This has prompted language revitalisation research, which has also motivated this study.

Globalisation enhances the transfer and sharing among different societies, whereas according to the ECT, assumes that the relationships among different groups are marked by power struggles. Therefore, ECT and globalisation feed on each other. ECT came as an afterthought following the natural amalgamation that was taking place due to globalisation.

\title{
5. Methodology
}

The study adopted a qualitative approach and data were collected using three instruments, namely interviews, focus groups discussions (FGD), and document analysis. Data were collected from radio audiences and station managers of the two indigenous language radio stations in the country using FGD and in-depth interviews respectively.

The researcher collected her data in the capital city of Zimbabwe, Harare, also known as the hub where all ethnic groups meet due to migration invoked by the economic, social, cultural and technological disparities between Harare and most places in the country (Sullivan and Brazier, 2012). Both national indigenous language radio broadcasting stations' head offices are also situated in Harare; Radio Zimbabwe (Mbare Studios) and National FM (Highlands).

The two radio station managers were interviewed and a total of 28 male and female radio listeners participated in four focus group meetings carried out in different high density locations in Harare. FGD 1 consisted of 6 participants (1415yrs); FGD 2 also had 6 participants (16 - 30 years). Eight (8) participants (30 - 45 years) were in FDG 3, while FGD 4 consisted of 8 participants all above 40 years. The participants were identified as Shona, Ndebele and minority language speakers (Venda, Chewa, Sotho, Shangani, Nambya, Kalanga and Tonga). Out of the 28 people who participated in the FGDs, 11 were Shona-speaking, 6 were Ndebele-speaking and 11 were minority language speakers. The Broadcasting Services Amendment Act herein referred to as the $\boldsymbol{A c t}$, and two weekly indigenous language radio station programme schedules were analysed.

\section{Data Presentation and Analysis}

The FGDs and interviews data were tape recorded with permission from the interviewees. These were then transcribed and coded for analysis. The findings were presented descriptively. Data were presented according to the instruments used to ensure that all the key issues were covered.

\section{Results}

The findings obtained are presented below.

\subsection{Interview responses}

The station managers were asked to state the languages used for broadcast on their stations and why.

The Radio Zimbabwe manager said:

\begin{abstract}
Radio Zimbabwe broadcasts in two local languages, Shona and Ndebele. We use Shona and Ndebele to broadcast because they are the two main indigenous languages in Zimbabwe which are spoken by the majority of the people. Why we use only two languages, I cannot say much since we are governed by the Broadcasting Act. It gives us guidelines on how we should operate; it is not for us to decide.
\end{abstract}

The radio Zimbabwe station manager also emphasised that in their station, they used Shona and Ndebele only, and that they did not allow their presenters to use slang or English even though slang is the in-thing for the youth. He said most of their listeners were Shona and Ndebele speakers or understood the two languages.

Echoing similar sentiments, the National FM manager said: "National FM broadcasts in 16 indigenous languages: 
Shona, Ndebele and 14 minority languages. The Broadcasting Act emphasised the need to broadcast in all the indigenous languages in Zimbabwe." According to the station manager, National FM broadcasts in the following languages: Shona, Ndebele, Shangani, Sotho, Venda, Xhosa, Chikunda, Doma, Chewa, Yao, Hwesa, Barwe, Kalanga, Nambya and Tonga. The National FM manager added to the confusion on the actual number of languages used on the station since his comments on the number of languages on National FM were contradictory. He elucidated that on paper the station was supposed to be using 16 languages including Khoisan. However, since its inception, the station has never really used this minority language.

Although both station managers mentioned the same Act, they did not agree on the actual number of languages required by this law for broadcasting. The Radio Zimbabwe interpreted the law as stating the need for ZBC to use the two main indigenous languages, whilst National FM believes the same law requires ZBC to broadcast in most, if not all, indigenous languages used in Zimbabwe.

\subsection{Focus group discussions responses}

Table: 1 Summary of FGD Participants' Identified Features

\begin{tabular}{|l|l|}
\hline Station & Features identified \\
\hline Radio Zimbabwe & $\begin{array}{l}\text { Indigenous languages, informative, educational, cultural issues, politics, local music, sports, } \\
\text { entertainment, political advertising. }\end{array}$ \\
\hline National FM & Various indigenous languages, political advertising. \\
\hline Power FM & English, entertainment, focus on youth entertainment, music. \\
\hline Spot FM & English, entertainment, variety music. \\
\hline
\end{tabular}

\subsection{Document analysis}

In order to verify the issues raised by the two managers, the researcher consulted the Act. It outlines specific licence conditions applying to public broadcasters. The Act states that the broadcasting service operated by a public broadcaster in Zimbabwe shall

(a) Make programmes available to Zimbabweans in all the languages commonly used in Zimbabwe;

(b) Reflect both the unity and diverse cultural and multilingual nature of Zimbabwe;

(c) Strive to be of high quality in all the languages served;

(d) Provide news and public affairs programming which meet the highest standards of journalism, and which is fair and unbiased and independent from government, commercial or other interests;

(e) Include significant amounts of educational programming, both curriculum-based and informal, including educative topics from a wide range of social, political and economic issues such as human rights, health, early childhood development, agriculture, culture, justice and commerce;

(f) Enrich the cultural heritage of Zimbabwe by providing support for traditional and contemporary artistic expression;

(g) Strive to offer a broad range of services aimed in particular at children, women, the youth and the disabled;

(h) Include programmes commissioned from independent producers; and

(i) Include programmes featuring national sports as well as developmental and minority sports. (BSA, 2007: 207)

The programme schedule from Radio Zimbabwe confirmed that this station strictly broadcasts in Shona and Ndebele on an equal basis. On the programme schedule, National FM programmes were listed in 13 minority indigenous languages (Shangani, Sotho, Venda, Xhosa, Chikunda, Doma, Chewa, Yao, Hwesa, Barwe, Kalanga, Nambya and Tonga) and Shona and Ndebele. On the National FM schedule, the duration and number of programmes and news bulletins, favoured Shona and Ndebele more than minority languages which were constantly alternated.

\section{Discussion}

Indigenous languages are very important in development (Ndhlovu, 2008), and radio is perceived as the far reaching medium which can help to promote the usage of these languages. However, there are fears that ILRBSs are not doing enough to protect the various indigenous languages which are slowly fading away. Various scholars concur that most indigenous languages are facing imminent language deaths (Skuntnabb-Kangas, 1981; Brenzinger, 1992; Crystal, 2003; Salawu, 2006; Manyozo, 2009; Mabika, 2011). 
All the FGD participants were more aware of the two indigenous languages used for broadcasting on Radio Zimbabwe than those used on National FM. Most of the youth participants disclosed that they were not familiar with most of the minority languages the station manager later identified, while the failure by adults to identify the language used on National FM also revealed their lack of knowledge of most of the languages. In some of their comments, the youth agreed with Mavesera's (2009) assertion that young people do not see the need to know these indigenous languages since they were not of any academic or economic benefit to them as is the case with English, Shona and Ndebele.

Indigenous languages are vital, to the speakers, since they allow people to think and express themselves freely. Radio broadcasting in indigenous languages is vital since it can help to add value to the dying languages, particularly among various social groups such as the youth who no longer see the value of their own languages. Indigenous language revitalisation involves the usage of moribund or threatened languages so that they can be gradually restored (Laoire, 2008). If exploited fully, radio is a mass communication medium that can offer almost limitless possibilities to minority languages and communities (Ndamba, 2008). However, the way the broadcasting stations in Zimbabwe are used to broadcast in these languages, will help to determine the success or failure of the revitalisation effort.

Allowing listeners to speak in their languages encourages them to participate fully in various discussions, and to contribute in decision-making on issues affecting their everyday lives. When a language, which is understood, is used, the radio station facilitates effective communication. However, if a language that is not well understood is used, the radio station becomes a hindrance to effective communication (Webb, 2002). Each time the station switches to a language not understood by speakers of minority languages, the station frustrates these listeners. They are left with no choice, at that particular time, but to search for alternative entertainment which might not really be in their language, but in universal languages such as English. This renders the assertion that indigenous languages can enhance overall cognitive development of the speakers a joke.

Some participants said English radio broadcasting stations were more entertaining than ILRBSs. The Radio Zimbabwe station manager agreed to this assertion pointing out that a station such as Power FM attracted young listeners because it is entertainment focused in a language understood by most young people. However, according to this station manager, ILRBSs in the country were guided by the Act, which restricts the stations from producing specific entertainment-focused programming only. This is confusing because the Act does not elaborate on the conditions that should be adhered to by a single station since it only states guidelines for "public broadcasters." This has been detrimental to ILRBSs efforts to produce competitive programming, which can also attract young listeners, and monolingual or bilingual listeners in the case of National FM. On the contrary, English stations such as Power FM, though guided by the same policy do not seem to be adhering to many guidelines. This has made English stations more attractive options for the youth, who prefer listening to a language they are familiar with instead of being bombarded in languages they cannot understand when they listen to National FM.

However, commenting on the stance taken by most young participants in identifying with English stations, Magwa (2008) pointed out that the actual reason why the youths preferred English stations is that they think English is associated with the rich and powerful. The youth naturally wanted to be part of the prestigious English-speaking community.

The study findings also reveal that most listeners, including the youth, often listen to Radio Zimbabwe since they are aware of the languages used for broadcasting on the station. Shona and Ndebele are widely understood in Zimbabwe. These languages, therefore, can be safely used on national stations unlike minority languages, which are understood by very few people. This makes Radio Zimbabwe's efforts to uphold the principal languages worthwhile and National FM's effort to be the multilingual mouth piece a fallacy.

The languages of Zimbabwe receive recognition based on the number of speakers. People place economic value on the language according to the prestige it is given nationally. Thus, English has remained the most powerful language, followed by Shona and Ndebele. The official minority languages take the third position and the rest are not recognised. Tonga Nambya, Kalanga, Sotho, Venda and Shangani are the other six officially recognized minority languages in Zimbabwe (Thondlana, 2002). However, according to Kadodo et al. (2012), although the principal indigenous languages are ranked a stratum above other indigenous languages, they are not treated any differently. According to the education system in place in Zimbabwe, English has continued to be the principal language of instruction to date (Zindoga, 2011). Students cannot qualify to proceed with their studies to advanced level or tertiary institutions if they fail to pass English. However, a pass in English and four other subjects can guarantee entry in institutions of higher learning even if some students might not have done any indigenous language/s.

Explaining a similar linguistic problem in neighbouring South Africa, even though indigenous languages are a prerequisite for university enrolment, the country's higher education minister shifted the blame to the speakers of the languages themselves (Szabo, 2011). He said that even though African languages are still being used by some radio stations, the real threat facing African languages is the speakers' attitudes. 
In Zimbabwe, the speakers' attitudes towards their languages were nurtured by the language policies adopted since independence in 1980. Masevera (2011:73) confirms this view when he says that "in a multi-lingual society, the language that is given an official status is usually the language of those who have both economic and political power." ILRBS, like all the other systems in the country, have done very little to improve the standing of minority languages. The features of the only two ILRBSs in the country clearly reveal a disparity that requires urgent attention if this medium of mass communication is to have any significant impact in the revitalisation of indigenous languages.

The programme schedules also revealed interesting linguistic trends. The Radio Zimbabwe schedule shows that the majority of its programmes use similar names and formats in Shona and Ndebele. Although this might be appreciated by monolingual Shona or Ndebele speakers, to multilingual Zimbabweans, the channel is repetitive. Mano (2006:287) points out that even though the dual language policy adopted by Radio Zimbabwe was meant for monolingual listeners, there were significant amounts of idle listening.

The National FM schedule revealed that most programmes had English names even though they were broadcast in indigenous languages. This is not reflective of the cultural issues covered in the programmes and, to some extent, can confuse the programme presenters and listeners. English terms do not really carry similar meanings when translated into indigenous languages.

Nevertheless it is interesting to note that the Radio Zimbabwe programme schedule, though mostly written in Shona and Ndebele, still fails to completely avoid using the English language. It contains a few English terms for programmes such as public notices, the weather report, the interlude and national anthem. These words can be interpreted in indigenous languages. For example, the weather report can be translated "Mamiriro ekunze". However, some names such as 'public notices' and 'interlude' are shorter and easier to identify with unlike their indigenous language translation. Lamenting on the scarcity of some simple indigenous language terminologies, Mazuruse and Mberi (2012) said that during Shona lectures, the lecturers have no choice but to switch to the English language, primarily because of lack of relevant terminology or technical terms in Shona.

Although issues of terminology, especially in relation to indigenous languages, have been advanced in this study and by other scholars in Africa and globally, the ILRBSs programme schedule reveals a need for Zimbabwean terminographers to go back to the drawing board to develop indigenous languages (Mazuruse \& Mberi, 2012). Globally, languages shift and change over time and new words are added to the existing dictionaries. This should not be viewed by indigenous language terminologists as exceptional and undoable. Africans should realise that all languages, just like cultures, are not static, but are ever changing. Hence, there is need to continue developing new terms instead of allowing indigenous languages to become out-dated and irrelevant over time.

Giving indigenous language programmes English names deprives the listeners and the presenters a chance to develop their unique ways of interacting with the programmes. Language is an aspect of culture that brings out hidden cultural connotations. When using English names for the programmes, alien cultural connotations attached to these terms might end up corrupting the languages, which are then used to present the English labelled programmes. This can also affect the content that is enshrined in such programmes since content normally has to relate to the name of the programme.

Most focus group participants who preferred indigenous language stations said that they see Radio Zimbabwe as informative and educational. Mano (2006: 274) states that Shona is, by far, the biggest language group and Ndebele, though spoken by $16,5 \%$ of the population, has, over the years, acquired a national character (Mano, 2006). However, Hadebe (1998) maintained that the status of Ndebele and Shona is mainly 'honorary', and that language practices in Zimbabwe do not reflect any significant changes from the practices of the colonial era. This means that, though Shona and Ndebele are, officially national indigenous languages due to the number of speakers who speak them, English has remained the dominant language of broadcasting and other spheres of official government business.

Some of the participants criticised the two indigenous language radio stations, particularly Radio Zimbabwe, for covering too much politics, a characteristic many find disgusting. They also felt that the political issues covered on the stations were openly biased since no interpretations or critical discussions were made. This trait, which was expressed by the study participants, is worrisome, taking into consideration the expected role of indigenous language broadcasting as outlined in the Act.

The BSA, 2001 "Seventh Schedule" (Section 11 (1) (b1)) Part I of the 2007 amendment subsection (e) and (f) states that a public broadcaster should strive to include significant amounts of educational programming, both curriculum-based and informal. This should include educative topics from a wide range of social, political and economic issues such as human rights, health, early childhood development, agriculture, culture, justice and commerce. Broadcasting programming is also expected to enrich the cultural heritage of Zimbabwe by providing support for traditional and contemporary artistic expression. The domination of political advertising thus undermines the provisions of 
the Act.

Stating a similar sentiment, Langa (2012:1) explains that, currently, ZBC represents a certain public because they have been turned into a broadcaster serving narrow political partisan interests. The government should allow the public broadcaster to operate as a public domain where people can freely discuss social, economic and even political issues without fear or favour, as is clearly stated in the Act. However, ZBC in general and ILRBSs, in particular, cannot afford to be used as mouth pieces of the ruling elite at the expense of covering developmental issues since these stations are listened to by the majority of people in the country.

According to the Act, ILRBS, by its nature, should help to uphold, revitalise and develop local languages, particularly minority languages, which have generally been sidelined over the years. Bemoaning the erosion of the Shona language, Mavesera (2009:8) said "this situation whereby the people have lost belief in their language, heritage, and capacity and ultimately in themselves retards their development and it simply emphasises the effects of colonialism".

\section{Findings within the Globalisation and the EC Theory}

All the FGD participants agreed that they are not familiar with most of the minority languages that are used for broadcasting on National FM which resonates with the globalisation theory. The theory states that global interactions have increased the demand for proficiency in some languages at the expense of others. The globalisation theory delineates that, in the new world order, when various languages and cultures meet, only the few stronger ones survive. Shona and Ndebele, used on Radio Zimbabwe, according to this study, seem to have successfully pushed out the various minority languages. Data revealed that some of the youth whose languages were in the minority cluster of languages opted to be known as Shonas or Ndebeles. They were ashamed to be associated with languages that had no economic or academic value in the globalised world. In the new world order, people attach economic value to anything that they do, including the languages they use to communicate.

The study revealed that youths and adults are agreed that the English language is vital since it is the language of education and power. This confirms the EC theory which assumes that the imbalances in power relations globally have resulted in the increased dependency of developing societies on the developed nations. Third world countries now heroworship anything originating from the developed world, including the English language, which is associated with success.

The government's language policies further marginalise indigenous languages in favour of English, thus, in a way, putting ILRBSs in a quandary. English has now been promoted and is seen as the language of power and economic prosperity. The government and business now rely on English at the expense of indigenous languages, which have no prestigious positions in the global world. This confirms the negative impact of globalisation mentioned by Nsibambi (2001) who argues that "As cultures interact, some cultures are being diluted and/or destroyed at the expense of others and negative values are being spread all over the world with relative ease" Nsibambi, 2001:2).

However, even though most youths in this study preferred English language radio broadcasting stations such as Power FM and SFM, the majority of the participants, including the youth, also agreed that they understood issues better in their indigenous languages. It is not a natural process for an audience to be only influenced by the global content since there are other external forces, such as understanding, that can interfere with this process. People are influenced by what they understand more than what they cannot comprehend. This contradicts the ECT and the globalisation theories which assume that media audiences, particularly those in developing nations such as Zimbabwe, are passive consumers of global media content. Misunderstanding alien cultures is more dangerous to the receiving nations. For instance, youth in developing countries can end up adopting indecent cultures which are contrary to both their own norms and that of the developed world they want to imitate. The globalisation and ECT theorists fail to bring out the implications of misunderstanding and adopting inappropriate languages and cultures by both the receiving and producing nations.

According to both the globalisation approach and the ECT, the interaction of participants, particularly young people, with the English language and global cultures is inevitable. McPhail's theory proposes that the influence of economically stronger nations such as the English-speaking nations on weaker countries, such as Zimbabwe, is premeditated, and effective. The ECT refers to this process as the modern form of colonialism, which may alter indigenous cultures and the socialisation processes overtime. The theory ignores the fact that when different societies become amalgamated, the different cultures that come into contact, whether developed or not, inevitably influence each other, in terms of language and culture. This has seen the many different "pidgin" English words that have sprouted around the world (BBC News 2006). Different groups of people have developed their own English language, which consists of a combination of English and other indigenous languages.

Thus, the theory is not critical enough to consider the reverse impact. It only concentrates on the negative impact of mass media on the developing world and overlooks the same impact on the developed societies which come into 
contact with alien cultures through the same media processes alluded to by both theorists.

FGD participants mentioned another interesting feature of the ILRBS. They said that there is too much political content on ILRBSs. This resonates with the globalisation theory which argues that audience, in this case Zimbabwean audiences, have shifted from just being local citizens to global audiences. Thus, they are no longer just influenced by the Zimbabwean media and government. They are also active participants in global politics. Generally, the Zimbabwean government has been under global media attack since the turn of the century. Willems (2005) narrated how the British media, when reporting on Zimbabwe, have departed from the agreed ethics, in order to effectively smear their former colony's current government and leader. The Zimbabwean audience, just like the other global audiences, are also fed with the subjective news on Zimbabwe through various media technologies, which according to the EC theory, are received passively. Nkosi Ndlela concurs when he states that the Western media coverage of Africa involves the concepts of framing and representation. He argues that:

Framing is the manner in which an issue is presented and this influences the way in which issues or problems can be understood. The media do not merely reflect the reality in Africa, they also recreate and reshape it through signifying practices and representation (Ndlela, 2005:72).

Therefore, the participants' hatred of political content on Radio Zimbabwe is consistent with the two theories used in this study, which concur on the effectiveness of developed nations' influence on developing nations. It can be safely argued that the respondents' position reveals the extent to which McPhail's theory is correct on the impact of global media messages on consumers in dependent societies.

Despite the numerous labels over the years, McPhail (2010) asserts that any interaction between the people in the developing world and those in the developed world is nothing but another label of cultural imperialism and has a tendency of ingraining the dependency syndrome. This was proven by some youths who openly rejected their own languages and music in favour of international music and content.

The features of the two ILRBSs in Zimbabwe, discussed in relation to the two theories adopted for this study, revealed both strengths and weaknesses of the two theories.

\section{Conclusion}

In order to verify the usefulness of indigenous language radio broadcasting in revitalising indigenous languages, the study assessed the various features of the two ILRBSs in Zimbabwe. The following conclusions were reached:

- ILRBSs are not doing much to change the listeners' colonial mind-set in terms of languages and their values.

- The current broadcasting set-up where 15 languages are squashed into a single station has bred dislike of the various minority languages spoken in the country.

- The ILRBSs' effort to promote indigenous languages are largely futile because of social stereotypical perceptions that indigenous languages are not good enough since they are of no academic or economic benefit to speakers.

- Youths feel caged and limited by ILRBSs to what they already see every day and know; they want adventure and new unfamiliar content.

- The usage of indigenous languages for radio broadcasting in Zimbabwe is frustrated by the vague broadcasting law.

- ILRBSs can be effective tools in enhancing the use of indigenous languages in multilingual societies such as Zimbabwe. However, the two existing ILRBSs were insufficient.

- It is not easy for national stations to satisfy all its target audiences in multilingual and multicultural Zimbabwe.

\section{Recommendations}

- The government must make some effort to add value to the various indigenous languages spoken in the country by adopting new policies which would allow the wide use of indigenous languages, for example, in education.

- Language development should be encouraged and ILRBS should play a major role in ensuring that this process does not result in indigenous language erosion. For instance, speakers of endangered languages must not borrow terms to replace existing indigenous language terms. Terms should only be borrowed and adjusted when the term does not exist in the indigenous language.

- In order to attract the youth, there is need for ILRBSs to develop radio stations targeting the youth. 
- There is need for Zimbabwean legislators to revisit the existing broadcasting law in any effort to rectify the established weaknesses.

- Each language group, no matter how small, should be represented by a community radio broadcasting station and the bigger language groups can have more radio stations, in order to cover their own group dynamics.

- The study recommends that National FM should transform from a national radio station to a provincial radio station, to enable it to cover a reasonable number of languages.

\section{References}

Brenzinger, M. (Ed.). (1992). Language Death: Factual and Theoretical Explorations with Special Reference to East Africa. Berlin: Motuton de Gruyter.

Browne, D. R. (2008). Talking the Talk on Indigenous Radio. Retrieved May 23, 2011, from Cultural Survival.org: http://www. culturalsurvival.org/print/3506

Chari, T. J., Bvuma, T. S., \& Maputseni, C. (2003). Media and Communication in Zimbabwe and Africa. Mount Pleasant: The Zimbabwe Open University.

Childs, P., \& William, P. J. (1997). An Introduction to Post-Colonial Theory. London: Prentice Hill.

Crystal, D. (2003). English as a Global Language. UK: Cambridge Press.

Deacon, G. (2009). Rhodesia RBC Bulawayo 683 kHz QSL Springbok Radio. Retrieved April 18, 2012, from http://capedx. blogspot.com/2009_12_01archive.html

Fourie, P. J. (Ed.). (2001). Media Studies: Institutions, Theories and Issues (Vol. 1). Lansdowne: Juta.

Giddens, A. (1990). The Consequences of Modernity . Cambridge: Polity.Kamwendo, G. (2008). But having Small Houses Spreads HIVProblems of Hadebe, S. (2003). Reflections on the Proposed Ndebele-Shona/Shona-Ndebele Dictionary. Eighth International Conference of the African Association for Lexicography (pp. 265-275). Windhoek: Lexikos.

Hadebe, S. (2003). Reflections on the Proposed Ndebele-Shona/Shona-Ndebele Dictionary. Eighth International Conference of the African Association for Lexicography (pp. 265-275). Windhoek: Lexikos.

Kadodo, W., Kadodo, M., Bhala, T., \& Bhebe, C. (2012). The Influence of Teachers and Students' Language Attitudes Towards the Use of Shona as Medium of Instruction in Secondary Schools. International Journal of English and Literature , 3 (2), 32-39.

Kamwendo, G. (2008). But having Small Houses Spreads HIV- Problems of Language and Communication in Health Services in SubSaharan Africa. In C. Stark (Ed.), Globalization \& Languages: Building on Our Rich Heritage (pp. 27-28). Tokyo: UNESCO.

Langa, V. (2012, October 6). Why Zimbos are not Paying ZBC Licenses. Newspaper

Laoire, M. O. (2008). Indigenous Language Revitalisation and Globalization. Te Kaharoa , 1, 203-216.

Mabika, M. (2011). Globalisation, Local Content Policy and Youth Culture in Zimbabwe. Germany: VDM Verlag Dr. Muller e. K.

Magwa, W. (2008). Planning for the Future: Exploring Possibilities of Using Indigenous African Languages as Languages of Instruction in Education - The Zimbabwean Experience. Thesis submitted in accordance with the requirements for the Degree of Doctor of Literature and Philosophy: UNISA.

Magwa, W. (2010). The Language Question in the Constituion Reform Process in Zimbabwe: A Closer Look at Linguistic Policies Outlined in the KaribaDraft Document. Zimbabwe International Journal of Language and Culture , 1 (1), 7-18.

Mano, W. (2006). African Public Service Radio versus National Languages: Mixed Responses to Radio Zimbabwe's Bilingual Service. In A. Salawu (Ed.), Indigenous Language Media in Africa (pp. 271 - 306). Lagos, Nigeria: Centre for Black and African Arts and Civilization (CBAAC).

Manyozo, L. (2009). Mobilizing Rural and Community Radio in Africa. Ecquid Novi: African Journal Studies , 30 (1), 1-23.

Maseko, B., \& Moyo, M. (2013). Minority Language Revitalisation in Zimbabwe-Fundamental Considerations for Tonga Language in the Zambezi Valley. Online Journal of Arts and Humanities, 2(10), 248-259.

Maseko, B., \& Ndlovu, K. (2013). Indigenous Languages and Linguistic Rights in the Zimbabwean Media. Online International Journal of Arts and Humanities , 2 (5), 150-156.

Mavesera, M. (2009). Empowerment Through Lnaguage: Exploring Possibilities of Using African Languages and Literature to Promote Socio-Cultural and Economic Development in Zimbabwe. University Of South Africa, African Languages. Johannesburg: UNISA.

Mavesera, M. (2011). Situating African Languages in the Global Village for Sustainable Development: Attractions and Challenges for Zimbabwe. Journal of Language and Culture , 2 (5), 72-81.

Mazuruse, M., \& Mberi, E. N. (2012). Language Raising, Empowerment and Development: The Case of Shona Language at Great Zimbabwe University. Theory and Practice in Language Studies , 2 (10), 2024-2034.

McCombs, M. E., \& Shaw, D. L. (Spring 1993). The Evolution of Agenda Setting Research: Twenty-five years in the Market place. Journal of Communication , 43 (2), 58 - 67.

McPhail, T. (2010). eColonialism Theory: Hegemony and the Role of American Media. The Global Studies Journal , 1 (2), 45-54.

Miller, C. (2007, January 05). Zimbabwean Broadcasting: From Colin Miller: Zimbabwe. Retrieved January 23, 2013, from Zimbaber Broadcast History: http://www.oldradio.com/archives/international/zimb.htm

Mufwene, S. S. (2002). Colonisation, Globalisation and the Future of Languages in the Twenty-first Century. MOST Journal on Multicultural Societies, 19-48.

Mumpande, I. (2006). Silent Voices: Indigenous Language in Zimbabwe. Harare: Weaver Press. 
Ndamba, G. T. (2008). Mother Tongue Usage in Learning: An Examination of Language Preferences in Zimbabwe. The Journal of Pan African Studies , 2 (4), 171-188.

Ndhlovu, F. (2004). Is There Anything Minor About Minority Languages? Another Look at The Politics of Language in Zimbabwe. Retrieved February 14, 2010, from http://www.umes.edu/english/newalp/pdf/Conference/finex.pdf

Ndhlovu, F. (2008). Language and African Development: Theoretical Reflections on the Place of Languages in African Studies. Nordic Journal of African Studies , 17 (2), 137-151.

Ndlela, N. (2005). The African Paradigm: The Coverage of the Zimbabwean Crisis in the Norwegian Media. Westminster Papers in Communiaction and Culture (Special Issue), 71-90.

Nsibambi, A. (2001). The Effects of Globalization on the State in Africa: Harnessing the Benefits and Minimizing the Costs . Retrieved July 05, 2013, from UNPAN: http://unpan1.un.org/intradoc/groups/public/documents/un/unpan001978.pdf

Nyika, N. (2007). A Case Study of Civil Society Organisations' Initiatives for the Development and Promotion of Linguistic Human Rights in Zimbabwe (1980-2004). Thesis submitted in accordance with the requirements for the Degree of Doctor of Philosophy: Witwatersrand.

Pasura, D. (2006). Zimbabwe: Mapping Exercise Report. London: International Organisation for Migration.

Rao, N. (2009, November 28). Is English Really the Greatest Language in the World? Retrieved February 3, 2011, from BBC World Service: http://www.teachingrnglish.org.uk/forum-topic/english-really-greatest-language-worldD/A

Rauschenberger, E. (Fall 2003). It's only a Movie - Right? : Deconstructing Cultural Imperialism. Retrieved March 10, 2013, from http://politics.as.nyu.edu/docs//O/4600/rauschenberger_thesis.pdf

Salawu, A. (2006). 'Paradox of a Milieu: Communicating in African Indigenous Languages in the Age of Globalisatiion'. In A. Salawu (Ed.), Indigenous Language Media in Africa (pp. 1-20). Lagos, Nigeria: Centre for Black and Afcrican Arts and Civilization (CBAAC).

Sonderling, S. (2009). Media, Language and Discourse. In P. J. Fourie (Ed.), Media Stidues: Media Content and Media Audiences (pp. 83-115). Cape Town: Juta \& Co Ltd.

Skutnabb-Kangas, T. (1981). Bilingual or Not. Clevedon: Multilingual Matters Ltd.

Sullivan, M., \& Brazier, A. (2012). Rural Urban Linkages Zimbabwe. Retrieved September 12, 2012, from ACF International: http://www.actionagainsthunger.org.uk/fileadmin/contribution/pdf/Zimbabwe\%20ACF.pdf

Szabo, C. (2011, January 21). Is Democracy Destroying African Langiages in South Africa. Retrieved March 05, 2013, from Digital Journal: http://digitaljournal.com/print/article/302784

The Zimbabwe Broadcasting Act, 2001

The Zimbabwe Broadcasting Amendment Act, 2007

Thondhlana, J. (2002). Using Indigenous Languages for Teaching and Learning in Zimbabwe. Eric Clearinghouse.

Webb, V. (2002). Language in South Africa The Role of Language in National Transformation, Reconstruction and Development. Amstersam: John Benjamins Publishing Company.

Willems, W. (2005). Remnants of Empire? British Media Reporting on Zimbabwe. Westminister Papers in Communication and Culture (Special Issue), 91-108.

Zindoga, T. (2011, March 18). Is Mother Tongue out of Fashion. Retrieved March 18, 2011, from Herald: $h$ ttp://www.herald.co.zw 